\title{
Volumetric and Morphometric Analysis of Pineal and Pituitary Glands of an Indian Inedial Subject
}

\author{
M.S. Raghuprasad M. Manivannan \\ Biomedical Engineering Group, Department of Applied Mechanics, IIT Madras, Chennai, India
}

\section{Keywords}

Ayurveda $\cdot$ Siddha $\cdot$ Survive on sunlight $\cdot$ Level set active contours · Neurohormonal morphology

\footnotetext{
Abstract

Background: Inedia (Latin for "fasting") is the ability of a person to live without consuming food and water and to sustain solely by prana, the vital life force in Hinduism. According to Ayurveda, sunlight is one of the main sources of prana, and some practitioners believe that it is possible for a person to survive on sunlight alone. Purpose: In this study, we report the unusual sizes and volumes of both the pineal and pituitary glands in a subject with inedia state for nearly 70 years. Methods: The pineal and pituitary glands were located in the MRI of the subject from coronal, axial, and sagittal images. Segmentation of the pineal and pituitary glands was performed using level set active contours method. Results: The
}

\section{KARGER}

(C) 2019 S.Karger AG, Basel

E-Mail karger@karger.com

www.karger.com/aon overall volume, size, and shape of the glands were calculated as $38.7604 \mathrm{~mm}^{3}$ for the pineal gland and $272.552 \mathrm{~mm}^{3}$ for the pituitary gland and compared with that of the normal volumes (94.2 $\pm 40.65 \mathrm{~mm}^{3}$ and $320-718 \mathrm{~mm}^{3}$, respectively). Conclusion: It was found that the subject has significantly low pineal and pituitary volumes, which fall under the category of normal young child and we could show that the neurohormonal morphology of inedia subject is within childhood range.

(c) 2019 S.Karger AG, Basel

\section{Introduction}

Pineal and pituitary glands are very important neuroendocrine organs. The main hormone secreted by the pineal gland is melatonin, but the pineal also produces a number of other hormones, including arginine vasoto- 
cin. The pineal gland modulates gonadal activity, mediates responses to light, and alters pigment coloration. The pituitary gland hangs from the bottom of the hypothalamus at the base of the brain and sits in a small cavity of bone above the roof of the mouth. The pituitary gland consists of the anterior, intermediate, and posterior lobes which are connected to the hypothalamus by the hypophyseal stalk. Axons from the PVN and SON of the hypothalamus project through the infundibulum to terminate in the posterior lobe, which consists of neural tissue. The anterior and intermediate lobes of the pituitary consist of endocrine tissue, which receives hormonal stimulation from the hypothalamus through the blood vessels of the hypophyseal portal system in the pars tuberalis of the hypophyseal stalk. The pituitary gland produces 10 hormones: 6 from the pars distalis, 2 from the pars nervosa, and 1 from the pars intermedia, while j8endorphin is secreted from the pars intermedia and the pars distalis.

The size of the pineal and pituitary glands is related to its function or the abnormality [1]. Reference data for the normal pineal volume [2] and pituitary volume [3] have been reported.

In this study, we report the unusual size of the volumes of both pineal and pituitary glands in a subject with inedia (ability of a person to live without food and water for longer duration) for nearly 70 years. The motivation for this study is to find possible mechanisms of inedial state in humans that might lead to techniques inducing inedial state. From the MRI morphometric and volumetric analysis of pineal and pituitary glands, it was found that the subject has significantly low pineal and pituitary volumes which falls under the category of normal young child (5-10 years old). It can sustain in the inedial state for longer duration if the pineal and pituitary volumes are low and if the brain does not age in coordination with the body. In addition, no reference data have been established on the relation between inedia and low pineal and pituitary volumes; earlier studies have shown that there is no significant relationship between the total pineal volume and the age of the subject [4].

Our conjecture is that the subject's brain resembles that of a person in the age group of 5-10 years, although his body is aging over the course of time his brain still continues to function as a normal young child. From the morphometric and volumetric analysis of pineal and pituitary glands, it was found that the subject has significantly low pineal and pituitary volumes, which falls under the category of normal young child.

\section{Methods}

\section{Subject}

The study was conducted on an 82 -year-old male subject who claims to have been in the state of inedia for the past 70 years. The subject weighed $35 \mathrm{~kg}$ and was $158 \mathrm{~cm}$ in height.

\section{Image Acquisition}

In this study, we used MRI modality to analyze the evolving size of pineal and pituitary glands. The brain study was conducted on Philips Achieva MRI system with a magnetic field strength 3.0 T. Thin sections of MRI data was obtained using transverse and sagittal 3D volumetric T1 weighted TFE gradient echo. The width and height of the image was $250 \times 250 \mathrm{~mm}$. Depth $=146.40 \mathrm{~mm}$, voxel size $=1.04 \times 1.04 \times 0.60 \mathrm{~mm}$, resolution $=0.960$ pixels $/ \mathrm{mm}$. The file format was DICOM. The scanning sequence and scanning variant were GR and MP, respectively. The spacing between slices was $0.6 \mathrm{~mm}$. The slice thickness was $1.2 \mathrm{~mm}$. The receiving coil type was SENSE-NV-16. FOV $=24.0 \times 24.0 \mathrm{~cm}$, matrix size $=250 \times$ 250 , pixel bandwidth $=209.709$, and imaging frequency $=127.792$ $\mathrm{Hz}$.

\section{Medical Image Processing}

The raw data were processed using the MRIcron software (which is an open source software tool kit used for medical image processing, especially for MRI data) with voxel size $1.04 \times 1.04 \times$ $0.60 \mathrm{~mm}$. Multi Planar Reformation was performed to obtain the coronal, sagittal, and axial views (Fig. 1). The windowing and contrast factors were suitably adjusted to obtain a clear visibility of the pineal gland.

\section{Segmentation of Medical Data}

Medical image segmentation is used to solve a wide range of biomedical research problems: cancer detection, brain morphology, treatment planning, robot-guided surgery, etc. Segmentation is a valuable tool which exerts an important influence on neuroimaging research. In today's medical imaging scenario, robust tools are available, ranging from manual to semiautomatic to automatic segmentation, which provides high efficiency and accuracy for segmenting anatomical structures. Open-source segmentation and registration tools are becoming very popular these days, which enable researchers to develop a fast prototyping model. Active contour level set segmentation algorithm is a robust and elegant tool with high specificity and good accuracy [5]. In this study, we have used Insight Segmentation and Registration Tool Kit (ITK-SNAP) for segmentation of pineal gland. ITK is one such popular open source tool which is highly accurate and efficient for medical image segmentation, funded under the Visible Human Project by the US National Library of Medicine [6], which implements level set active contour segmentation. The scope of this study is limited to the segmentation of pineal and pituitary glands.

\section{Insight Segmentation and Registration Tool Kit}

The overall volumes of pineal and pituitary glands and statistics of the intensity of pixels for each segmented structure was calculated using ITK-SNAP 1.1 build version with Microsoft VC++ Express Edition Compiler. ITK-SNAP [5] is an open source tool kit, used extensively in academic and industrial environments, built on ITK C++ classes. The processed MRI data in DICOM format were 
Fig. 1. Multiplanar reformation of the raw MRI data with histogram.
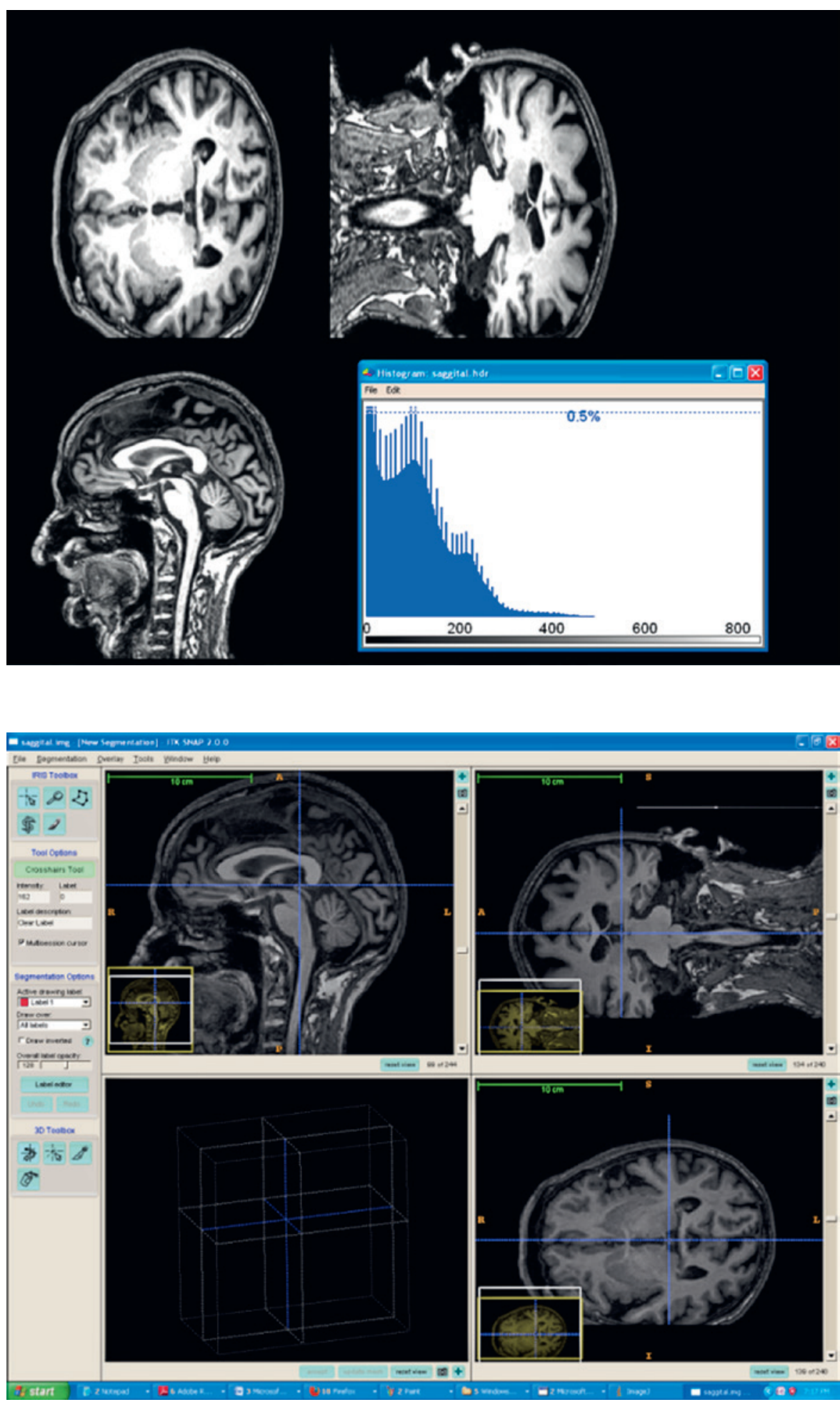

Fig. 2. GUI of ITK-SNAP showing MRI data in sagittal, coronal, and axial views.

loaded to the ITK-SNAP (Fig. 2) tool kit and the segmentation operation was performed to segment the pineal gland. Segmentation method adopted here is $3 \mathrm{D}$ level set active contour. SNAP provides a set of tools to make segmentation of volumetric data simpler and faster. SNAP can be used in 2 different modes: manual segmenta- tion and semi-automatic segmentation. The manual mode is used for segmentation using hand contouring and for cleaning up the results of automatic segmentation; many brain research laboratories use manual delineation as the technique of choice for image segmentation. In the semi-automatic mode, a powerful level set seg- 

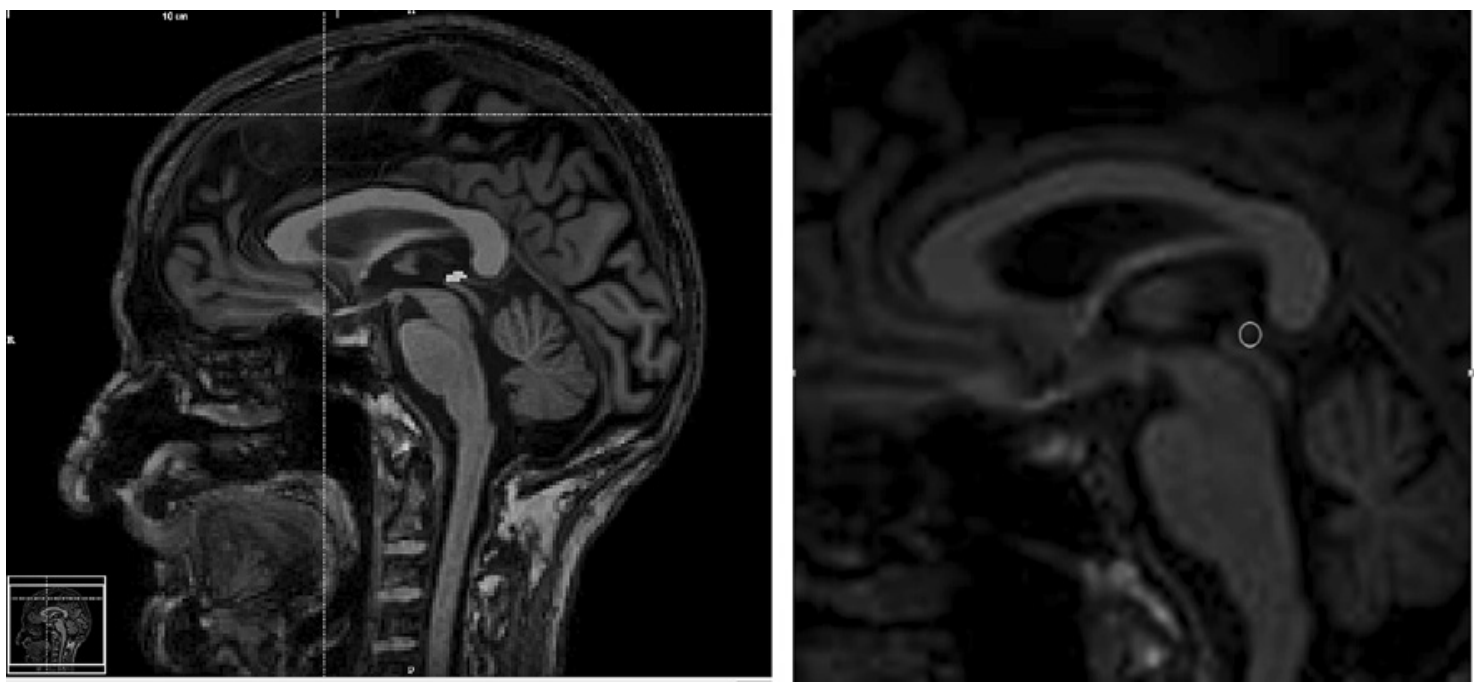

Fig. 3. Pineal gland marked in red on the sagittal section of the subject's MRI data.

Fig. 4. Selection of upper and lower threshold in the GUI of ITK-SNAP after performing cubic interpolation.
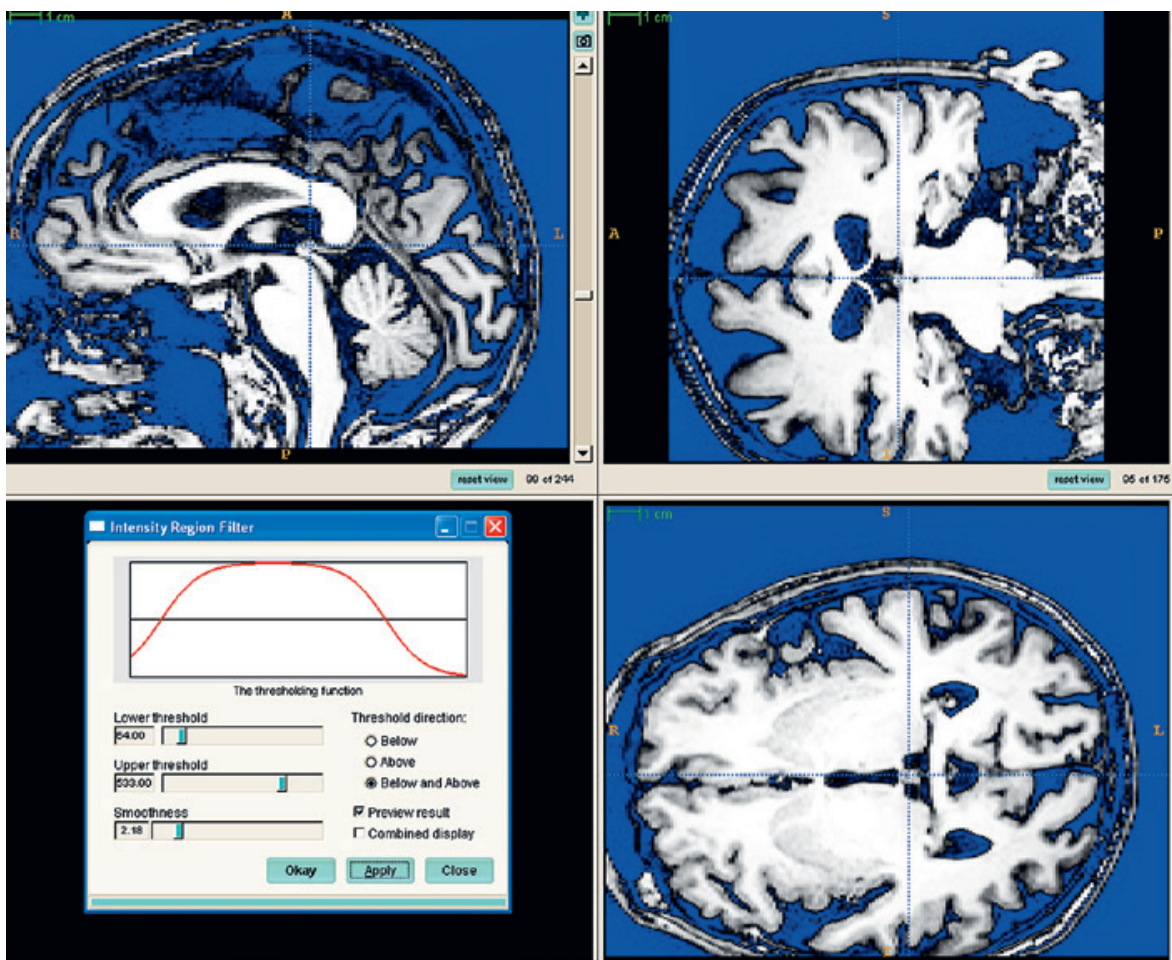

光尚

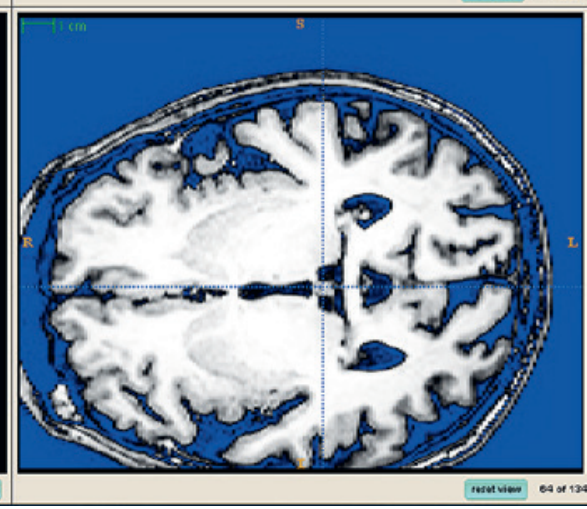

mentation algorithm is used to segment anatomical structures in 3 dimensions. ITK-SNAP has the ability to compute segmentation operation with region competition snakes and edge-based snakes.

Computation of Pineal Gland and Pituitary Gland Volumes

The overall pineal gland and pituitary gland volume was computed using semi-automatic segmentation algorithm, embedded in ITK-SNAP. The region/tissue of interest was selected (Fig. 3).
The data were resampled using cubic interpolation method. The upper threshold, lower threshold, and smoothness parameters were adjusted appropriately to enable high accuracy and specificity for the segmentation of pineal gland (Fig. 4). Level Set Active contour (snakes) algorithm was used to control the snake evolution or the movement of snakes in the pixel regions pertaining to the pineal gland and pituitary gland. The algorithm groups the pixels corresponding to pineal gland and pituitary gland into a 
particular class in all the slices of MRI data and calculates the volume in cubic mm.

ITK SNAP adopts level set active contour model [7-9] as shown below:

$$
A_{t}(t, u)=F_{\text {internal }}+F_{\text {external }}
$$

where $A(t, u)$ represents the contour at time $t$, with $\mathrm{u}$ being the variable value that is influenced by a duration of time $t . F_{\text {internal }}+$ $F_{\text {external }}$ are the 2 forces acting on the contour.

Computation of external forces by Caselles method is modeled in the following form:

$$
C_{t}(t, u)=\left(\alpha g_{I}+\beta k g_{I}+\gamma \nabla g_{I} \cdot N\right) N
$$

The modulating weights are represented by $\alpha, \beta$, and $\gamma$ parameters, respectively. $k$ represents the mean value of the contour.

In Caselles method of level set active contour computation, the calculation of the external forces is done from the gradient magnitude of the intensity of pixels. $\mathrm{N}$ represents the contour normal and $g_{I}$ denotes the normalized gradient magnitude function of image $I$

$$
\begin{aligned}
& g_{I=f_{\text {map }}}\left(\frac{\left\|\nabla\left(G_{\sigma} * I\right)\right\|}{\max \left\|\nabla\left(G_{\sigma} * I\right)\right\|}\right) \\
& f_{\text {map }}(x)=\frac{1}{\left(1+(x / v)^{l}\right.}
\end{aligned}
$$

$G_{s}{ }^{*} I$ represents the convolution operation with a Gaussian kernel. $V, \sigma, \lambda$ are the user-defined parameters.

The $3 \mathrm{D}$ volume rendering of the segmented pineal gland and pituitary gland structures was performed using marching cubes algorithm in visualization tool kit $[10,11]$. Visualization tool kit is independent of open source tool kit with $\mathrm{C}++$ core. ITK-SNAP utilizes visualization tool kit application programming interface for surface and volume rendering and meshing display.

\section{Previous Work}

Findings Related to Pineal Gland

Several radiological case studies are available where researchers have done rigorous analysis on the volume of pineal gland in normal and abnormal subjects. An extensive study conducted on pineal volume in healthy young adults by [2] reports that the mean pineal volume in the case of male adults with no cysts was estimated to be $89.21 \pm 28.78 \mathrm{~mm}^{3}$ and the true pineal volume in healthy adults was reported to be $94.2 \pm 40.65 \mathrm{~mm}^{3}$. A study pertaining to the evolving size of the pineal gland [1] reports that the size of the pineal gland was $26.9 \pm 12.4 \mathrm{~mm}^{3}$ (mean $\pm \mathrm{SD}$ ) in subjects with age greater than 2 years, and in patients with age ranging from 2 to 20 years the volume was observed to be $56.6 \pm 27.6 \mathrm{~mm}^{3}$ (mean $\pm \mathrm{SD})$.

A statistical study [12] on 80 human cadavers aimed at comparing the length, height, width, and volume of pineal gland with overall body weight, height, and age, reports that the average pineal volume was highest $\left(158.34 \pm 43.17 \mathrm{~mm}^{3}\right)$ in the age group of $31-40$ years, the lowest mean volume $\left(109.90 \pm 37.50 \mathrm{~mm}^{3}\right)$ was reported in the age group of 41-50 years; in the age group of less than 30 years, the pineal volume was found to be $131.47 \pm$ $41.42 \mathrm{~mm}^{3}$ and in those with age greater than 50 years the pineal volume was $124.97 \pm 39.79 \mathrm{~mm}^{3}$. In weight-related measures, the volume of pineal gland was observed to be highest in subjects with body weight less than $60 \mathrm{~kg}\left(140.08 \pm 49.63 \mathrm{~mm}^{3}\right)$, least in subjects with body weight greater than $80 \mathrm{~kg}\left(105.67 \pm 39.48 \mathrm{~mm}^{3}\right)$, and the pineal volume was found to be $130.79 \pm 63.97 \mathrm{~mm}^{3}$ in subjects with body weight ranging from 61 to $70 \mathrm{~kg}$ and $114.26 \pm 47.09 \mathrm{~mm}^{3}$ in subjects with body weight ranging from 71 to $80 \mathrm{Kg}$. In the heightrelated measurements, the pineal volume was observed to be lowest in subjects with height ranging from 171-175 cm (100.84 \pm $47.71 \mathrm{~mm}^{3}$ ), highest in subjects with height ranging from 165 to $170 \mathrm{~cm}\left(145.69 \pm 72.32 \mathrm{~mm}^{3}\right)$, in subjects with height less than 165 $\mathrm{cm}$ the pineal volume was found to be $138.74 \pm 52.89 \mathrm{~mm}^{3}$ and in subjects with height greater than $175 \mathrm{~cm}$ the pineal volume was reported to be $111.18 \pm 32.71 \mathrm{~mm}^{3}$.

Findings Related to Pituitary Gland

Whole pituitary volume has been reported by Takano et al. [13] as 0 years $=132.6 \pm 39.6,1-4$ years $=212.7 \pm 44.1,5-9$ years $=$ $309.9 \pm 54.9,10-14$ years $=423 \pm 110.3,15-19$ years $=586.2 \pm 149.8$ $\mathrm{mm}^{3}$. Ikram et al. [3] reports the pituitary volume of male subjects in the 3 age groups: in the first decade the volume was observed to be $116 \pm 62 \mathrm{~mm}^{3}(p=0.491)$, in the second decade, the volume was found to be $268 \pm 118 \mathrm{~mm}^{3}(p=0.079)$, and in the third decade the volume was found to be $309 \pm 117 \mathrm{~mm}^{3}(p=0.731)$. Under the age of 19 years, pituitary gland volume was strongly correlated with age $(r=0.46, p<0.0001)$, compared to that of older (20-35 years) subjects $(0.06, p=0.76)$ [14].

A study conducted by Ju et al. [15] on 33 human cadavers (23 were male cadavers in the age group of 23-87 years and 10 were female cadavers in the age group of 28-76 years) reports that in the anterior lobes the mean width, length, and height of the pituitary gland were found to be $14.3 \pm 2.1,7.9 \pm 1.3,6.0 \pm 0.9 \mathrm{~mm}$ and $8.7 \pm 1.7,2.9 \pm 1.1,5.8 \pm 1.0 \mathrm{~mm}$ in posterior lobes, respectively. Ertekin et al. [16] estimated the volume of 6 male pituitary glands with an age range of 35-66 years, using stereoscopic approaches such as point counting $\left(582.14 \pm 140.16 \mathrm{~mm}^{3}\right)$, planimetry $\left(610.08 \pm 133.17 \mathrm{~mm}^{3}\right)$, and elliptical formula $(390.99 \pm$ $\left.105.46 \mathrm{~mm}^{3}\right)$.

\section{Results}

\section{Volumetric and Morphometric Analysis of \\ Pineal Gland}

The pineal gland segmentation was performed in coronal, axial, and sagittal section views of the subjects' MRI data (Fig. 5; subset (a) shows pineal gland marked in sagittal section, subset (b) shows pineal gland marked in coronal section, subset (c) shows pineal gland marked in axial section, and subset (d) shows volume rendered image of pineal gland).

Table 1 shows the details of the volume of pineal gland computed from the MRI segmentation. The mean volume is $148.741 \mathrm{~mm}^{3}$ with a SD of $34.745 \mathrm{~mm}^{3}$. 

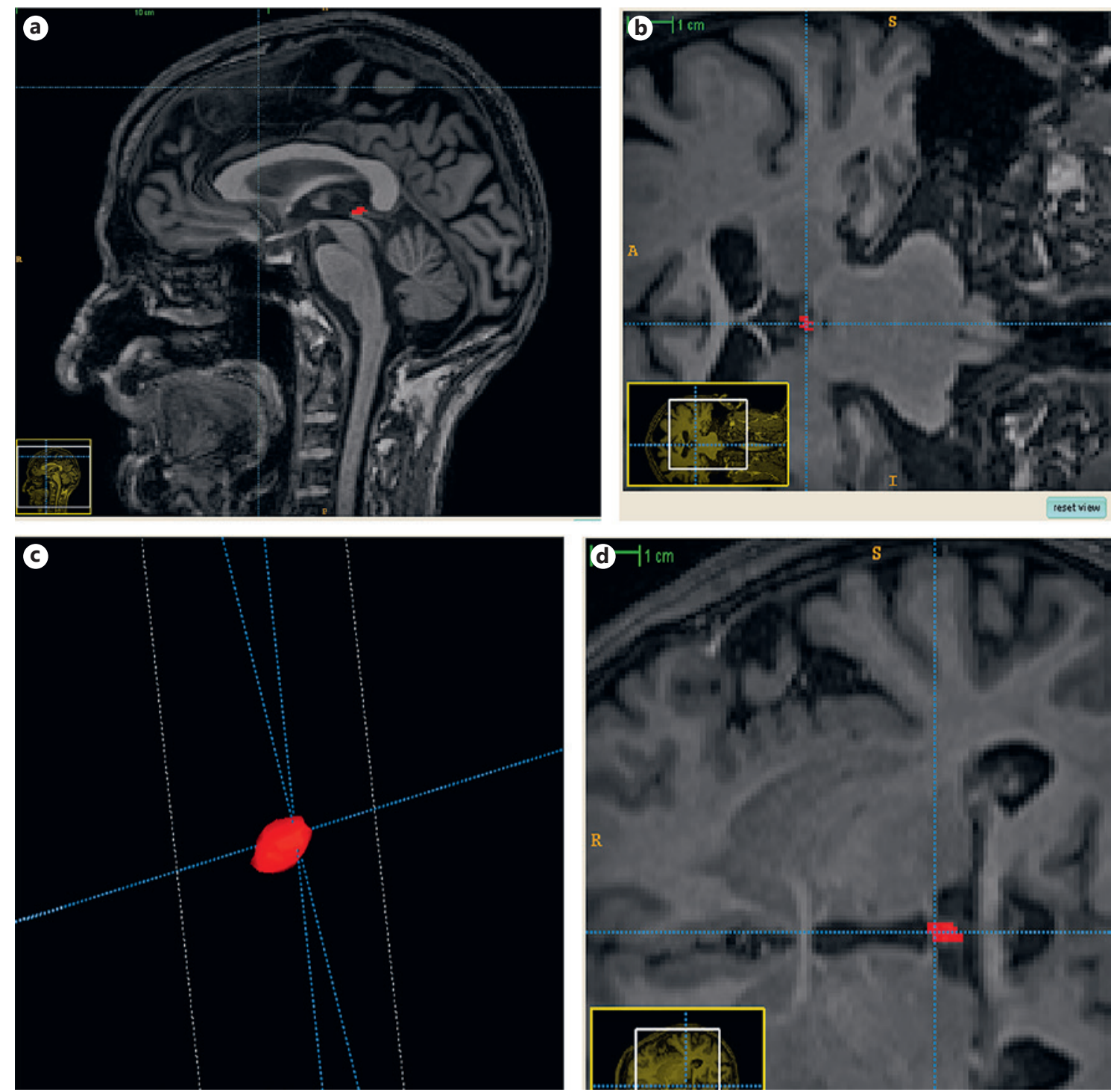

Fig. 5. Segmentation of pineal gland. a Pineal gland marked in sagittal section. b Pineal gland marked in coronal section. c Pineal gland marked in axial section. $\mathbf{d}$ Volume rendered image of pineal gland.

Table 1. Volume and statistics table of the pineal gland

\begin{tabular}{lllll}
\hline S. No. & $\begin{array}{l}\text { Number } \\
\text { of voxels }\end{array}$ & $\begin{array}{l}\text { Volume of } \\
\text { voxels, } \mathrm{mm}^{3}\end{array}$ & Mean & SD \\
\hline 1 & 58 & 38.7604 & 148.741 & 34.745 \\
\hline
\end{tabular}

Figure 6 shows the morphometric parameters of pineal gland. Subset (a) shows the height of the pineal gland on T1 weighted sagittal section, subset (b) shows the length of the pineal gland on T1 weighted sagittal section, and subset (c) shows the width of the pineal gland on T1 weighted axial section.

The maximum values of length $(4.8 \mathrm{~mm})$, width $(4.27$ $\mathrm{mm})$, and height $(3.8 \mathrm{~mm})$ of pineal gland are shown in Table 2.

The head circumference (C) was calculated based on the ellipsoidal assumption of the shape of the head when it is viewed axially, as shown in Figure 7. In this study, we used the Ramanujan's approximation formula to calculate the circumference of the head.

$$
\mathrm{C} \approx \pi[3(a+b)-\sqrt{(3 a+b)(a+3 b)}]
$$


Table 2. Maximum length, width, and height of pineal gland

\begin{tabular}{|c|c|c|c|c|c|c|}
\hline S. No. & $\begin{array}{l}\text { Maximum pineal } \\
\text { length, } \mathrm{mm}\end{array}$ & $\begin{array}{l}\text { Maximum pineal } \\
\text { width, } \mathrm{mm}\end{array}$ & $\begin{array}{l}\text { Maximum pineal } \\
\text { height, } \mathrm{mm}\end{array}$ & $\begin{array}{l}\text { Subject's } \\
\text { weight, kg }\end{array}$ & $\begin{array}{l}\text { Subject's } \\
\text { height, } \mathrm{cm}\end{array}$ & $\begin{array}{l}\text { Subject's head } \\
\text { circumference, mm }\end{array}$ \\
\hline 1 & 4.8 & 4.27 & 3.8 & 35 & & 506.566 \\
\hline
\end{tabular}
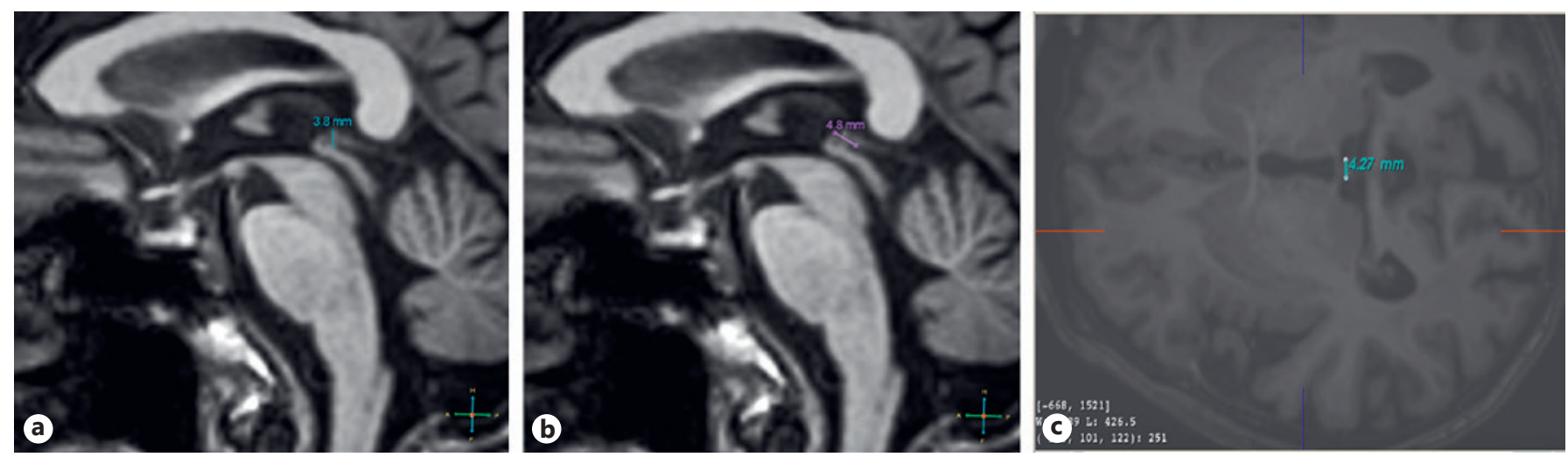

Fig. 6. Morphometric parameters of pineal gland. a Height of the pineal gland on T1 weighted sagittal section. b Length of the pineal gland on T1 weighted sagittal section. c Width of the pineal gland on T1 weighted axial section.

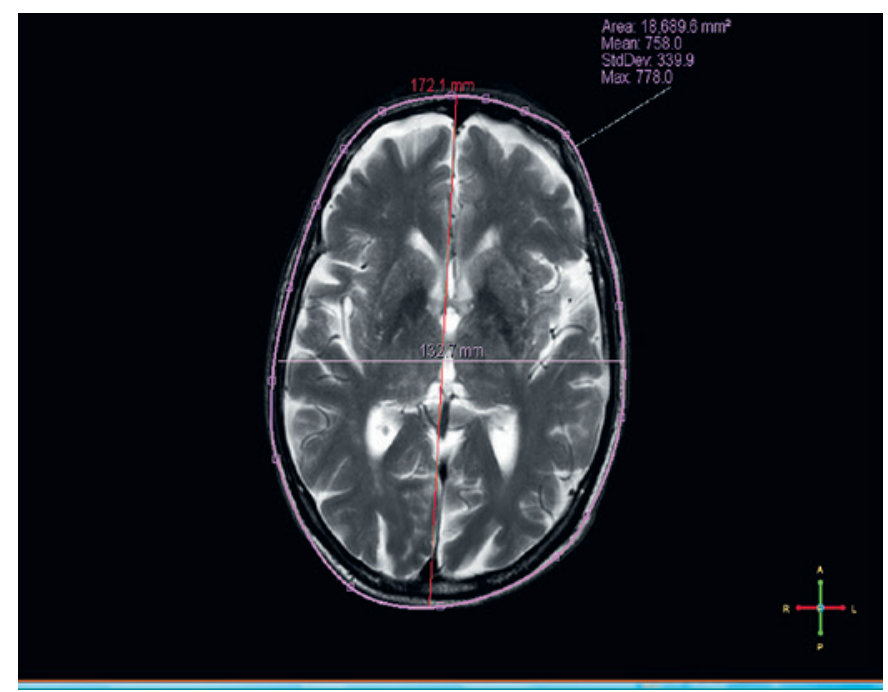

Fig. 7. Area of head.

\section{Volumetric and Morphometric Analysis of \\ Pituitary Gland}

Not only is the pineal gland of the subject measured, but also the pituitary gland. Figure 8 shows the segmentation of the pituitary gland, subset (a) shows the pituitary gland marked in the sagittal section, subset (b) shows it in the coronal section, subset (c) shows it in the axial section, and subset (d) shows the volume rendered image of the pituitary gland.

Table 3 shows the details of the volume of pituitary gland computed from the MRI segmentation. The mean volume is $264.412 \mathrm{~mm}^{3}$ with a standard deviation of $58.537 \mathrm{~mm}^{3}$.

Figure 9 shows the morphometric parameters of the pituitary gland, such as the height (subset a), length (subset b), and width (subset c) of the pituitary gland on T1 weighted axial section.

The maximum values of length $(10.00 \mathrm{~mm})$, width $(10.5 \mathrm{~mm})$, and height of pituitary gland $(4.7 \mathrm{~mm})$ are shown in Table 4.

\section{Discussion}

The pineal gland volume $\left(38.7604 \mathrm{~mm}^{3}\right)$ of the inedia subject is much smaller than the normal adult volume $94.2 \pm 40.65 \mathrm{~mm}^{3}$. The height, width, and length of the pineal gland is small $(3.8,4.27$ and $4.8 \mathrm{~mm})$ compared to the morphometric findings reported by Sun et al. [2] $(3.85,6.92,6.64 \mathrm{~mm})$. Compared to the subject's age, his pineal volume is less; when compared to age 

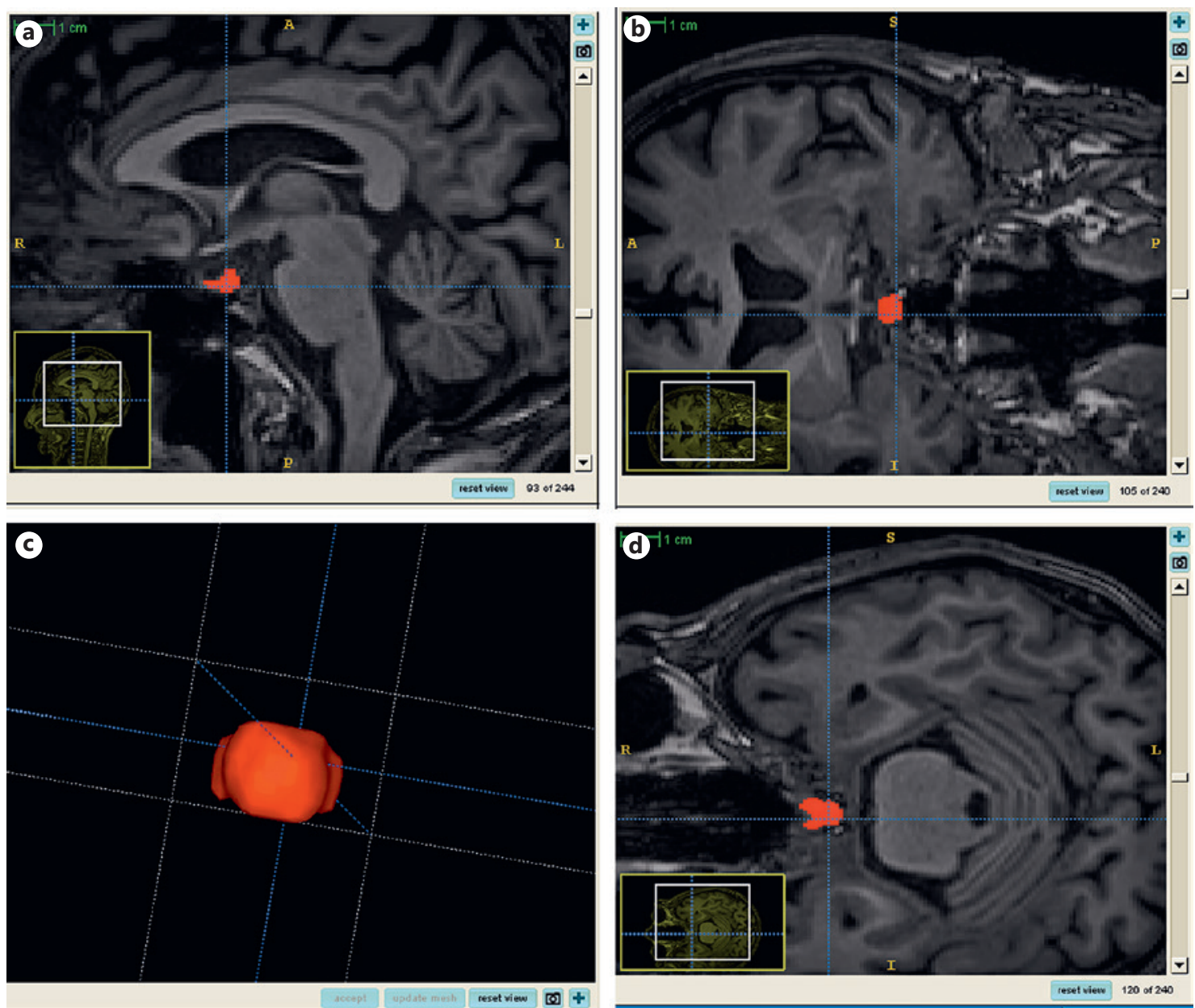

Fig. 8. Segmentation of the pituitary gland. a Pituitary gland marked in the sagittal section. b Pituitary gland marked in the coronal section. c Pituitary gland marked in the axial section. $\mathbf{d}$ Volume rendered image of the pituitary gland.

Table 3. Volume and statistics table of the pituitary gland

\begin{tabular}{lllll}
\hline S. No. & $\begin{array}{l}\text { Number } \\
\text { of voxels }\end{array}$ & $\begin{array}{l}\text { Volume of } \\
\text { voxels, } \mathrm{mm}^{3}\end{array}$ & Mean & SD \\
\hline 1 & 434 & 272.552 & 264.412 & 58.537 \\
\hline
\end{tabular}

and corresponding volume of healthy young adults and the circumference of head, the pineal volume is less in size. The pituitary volume $\left(272.552 \mathrm{~mm}^{3}\right)$ of the inedia subject is less compared to the normal pituitary volume, which is around $390.99 \mathrm{~mm}^{3}$ [16]. The height, width, and length of pituitary gland $(4.7,10.5$, $10.00 \mathrm{~mm}$ ) of the inedia subject is small compared to the normal findings on Korean adults reported by Ju et al. [15] ( $8 \mathrm{~mm}$ in length, $14 \mathrm{~mm}$ in width, and $6 \mathrm{~mm}$ in height).

A previous study by Fink et al. [17] determined the volume of pituitary gland and its height in normal children within 10 years of age. When we compared our results with this study we found that our results were similar, that is, our calculated pituitary volume $\left(272.552 \mathrm{~mm}^{3}\right)$ is found normally in male children with age range of 6-8 years and our calculated pituitary height of $4.7 \mathrm{~mm}$ corresponds to the volume of $272.552 \mathrm{~mm}^{3}$ in the volume versus pituitary height graph. Thus, the size of pituitary and pineal glands of the inedia subject falls in the range of 5-10 years in a normal child.

The purpose of this study is to put forth a hypothesis that the humans can sustain in the inedial state for longer duration if the pineal and pituitary volumes are low and 

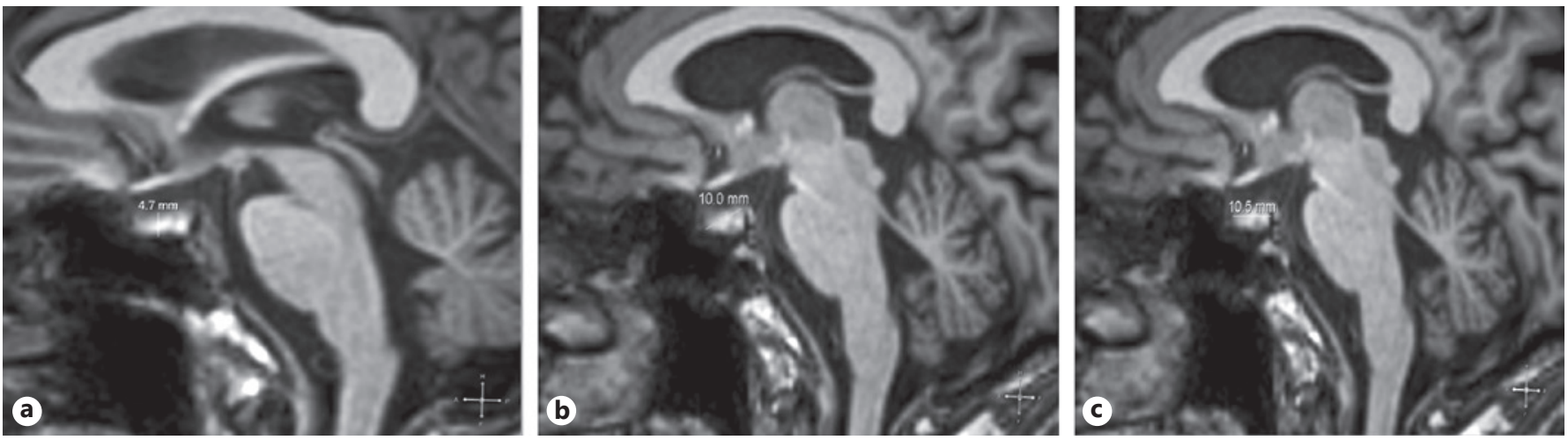

Fig. 9. Morphometric parameters of the pituitary gland. a Height of the pituitary gland on T1 weighted sagittal section. b Length of the pituitary gland on T1 weighted sagittal section. c Width of the pituitary gland on T1 weighted axial section.

Table 4. Maximum length, width, and height of pituitary gland

\begin{tabular}{lllllll}
\hline S. No. & $\begin{array}{l}\text { Maximum pituitary } \\
\text { length, } \mathrm{mm}\end{array}$ & $\begin{array}{l}\text { Maximum pituitary } \\
\text { width, } \mathrm{mm}\end{array}$ & $\begin{array}{l}\text { Maximum pituitary } \\
\text { height, } \mathrm{mm}\end{array}$ & $\begin{array}{l}\text { Subject's } \\
\text { weight, } \mathrm{kg}\end{array}$ & $\begin{array}{l}\text { Subject's } \\
\text { height, cm }\end{array}$ & $\begin{array}{l}\text { Subject's head } \\
\text { circumference, mm }\end{array}$ \\
\hline 1 & 10.00 & 10.5 & 4.7 & 35 & 158 & 506.566 \\
\hline
\end{tabular}

if the brain and its neuroendocrine morphology does not age along with the body. In addition, no reference data have been established on the relation between inedia and low pineal and pituitary volumes; earlier studies have shown that there is no significant relationship between the total pineal volume and the age of the subject [18].

From the morphometric and volumetric analysis of pineal and pituitary glands, it was found that the subject has significantly low pineal and pituitary volumes which falls under the category of normal young child.

Our observation is that the subject's brain resembles that of a person in the age group of 5-10 years, although his body is aging over the course of time his neuroendocrine morphology and functions still continues to remain as that of a normal young child. Although it is tempting to conclude that our hypothesis is true, due to the lack of clinical and hormonal profile of the inedia subject, we could only say that the neurohormonal morphology of inedia subject is within childhood range.

\section{Disclosure Statement}

We declare that we do not have any financial or other relationships that might lead to a conflict of interest. The manuscript complies with ICMJE guidelines.

\section{Author Contribution}

Both authors have contributed equally to this work.

\section{References}

1 Sumida M, Barkovich AJ, Newton TH: Development of the pineal gland: measurement with MR. AJNR Am J Neuroradiol 1996;17: 233-236.

2 Sun B, Wang D, Tang Y, Fan L, Lin X, Yu T, Qi H, Li Z, Liu S: The Pineal Volume: a threedimensional volumetric study in healthy young adults using 3.0 T MR Data. Int J Dev Neurosci 2009;27:655-660.
3 Ikram MF, Sajjad Z, Shokh IS, Omair A: Pituitary gland volume on magnetic resonance imaging: normative observations. Pak J Neurol Sci 2007;2:141-144.

4 Hasegawa A, Ohtsubo K, Mori W: Pineal gland in old age; quantitative and qualitative morphological study of $168 \mathrm{hu}$ man autopsy cases. Brain Res. 1987;409: 343-349.
5 Yushkevich PA, Piven J, Hazlett HC, Smith RG, Ho S, Gee JC, Gerig G: User-guided 3D active contour segmentation of anatomical structures: significantly improved efficiency and reliability. Neuroimage 2006;31:11161128.

6 Ibanez L, Schroeder W, Ng L, Cates J: The ITK Software Guide (ed 2). Kitware, Inc, 2005. 
7 Caselles V, Catte F, Coll T, Dibos F: A geometric model for active contours. Numerische Mathematik 1993;66:1-31.

8 Caselles V, Kimmel R, Sapiro G: Geodesic active contours. Int J Comput Vis 1997;22:6179.

9 Zhu SC, Yuille A: Region competition: unifying snakes, region growing, and bayes/MDL for multiband image segmentation. IEEE Trans Pattern Anal Mach Intell 1996;18:884900.

10 Lorensen WE, Cline HE: Marching cubes: a high resolution 3D surface construction algorithm. Comput Graph 1987;21:163-169.

11 Ibanez L, Schroeder W, Cates J: The ITK software guide: the insight segmentation and registration toolkit. Kitware Inc, 2003.
12 Golan J, Torres K, Staśkiewicz GJ, Opielak G, Maciejewski R: Morphometric parameters of the human pineal gland in relation to age, body weight and height. Folia Morphol (Warsz) 2002;61:111-113.

13 Takano K, Utsunomiya H, Ono H, Ohfu M, Okazaki M: Normal development of the pituitary gland: assessment with three-dimensional MR volumetry. AJNR Am J Neuroradiol 1999;20:312-315.

14 MacMaster FP, Leslie R, Rosenberg DR, Kusumakar V: Pituitary gland volume in adolescent and young adult bipolar and unipolar depression. Bipolar Disord 2008;10:101-104.

15 Ju KS, Bae HG, Park HK, Chang JC, Choi SK, Sim KB: Morphometric study of the Korean adult pituitary glands and the diaphragma sellae. J Korean Neurosurg Soc 2010;47:42-47.
16 Ertekin T, Acer N, Turgut AT, Aycan K, Ozçelik O, Turgut M: Comparison of three methods for the estimation of the pituitary gland volume using magnetic resonance imaging: a stereological study. Pituitary 2011;14: 31-38.

17 Fink AM, Vidmar S, Kumbla S, Pedreira CC, Kanumakala S, Williams C, Carlin JB, Cameron FJ: Age-related pituitary volumes in prepubertal children with normal endocrine function: volumetric magnetic resonance data. J Clin Endocrinol Metab 2005;90:32743278.

18 Hasegawa A, Ohtsubo K, Mori W: Pineal gland in old age; quantitative and qualitative morphological study of 168 human autopsy cases. Brain Res 1987;409:343-349. 